\title{
Metformin alleviates high glucose-mediated oxidative stress in rat glomerular mesangial cells by modulation of p38 mitogen-activated protein kinase expression in vitro
}

\author{
XIN-MING YAO, SHAN-DONG YE, CHUN-CHUN XIAO, JUN-FEI GU, DI YANG and SHAN WANG \\ Department of Endocrinology, Anhui Provincial Hospital Affiliated to Anhui Medical University, \\ Hefei, Anhui 230001, P.R. China
}

Received April 18, 2014; Accepted February 13, 2015

DOI: $10.3892 / \mathrm{mmr} .2015 .3446$

\begin{abstract}
The aim of the current study was to investigate the effects and mechanism of metformin in oxidative stress and p38 mitogen-activated protein kinase (p38MAPK) expression in rat glomerular mesangial cells (MCs) cultured in a high glucose medium. Rat glomerular MCs (HBZY-1) were cultured in complete medium and divided into the following five groups: Normal control (NC), high glucose (HG), metformin-treated, SB203580-treated (SB) and N-acetylcysteine-treated (NAC). The production of intracellular reactive oxygen species (ROS) in rat glomerular MCs was measured using flow cytometry. Superoxide dismutase (SOD) activity and malondialdehyde (MDA) content in the supernatant was detected using colorimetric analysis and an ELISA, respectively. p22phox mRNA levels in rat glomerular MCs were determined using reverse transcription-quantitative polymerase chain reaction. The levels of p22phox protein and phosphorylated p38 mitogen-activated protein kinase (p-p38MAPK) protein in rat glomerular MCs were determined by western blot analysis. Compared with the NC group, the activity of SOD in the supernatant was significantly reduced, whereas the levels of MDA in the supernatant, intracellular p22phox mRNA and protein, p-p38MAPK protein in addition to ROS production in rat glomerular MCs were significantly increased in the HG group $(\mathrm{P}<0.05)$. When metformin was added to the high glucose medium, the activity of SOD in supernatant fluid was increased significantly, whereas a significant reduction $(\mathrm{P}<0.05)$ was observed in the levels of MDA in the supernatant, intracellular p22phox mRNA and protein, p-p38MAPK protein in addition to ROS production in rat glomerular MCs.
\end{abstract}

Correspondence to: Professor Shan-Dong Ye, Department of Endocrinology, Anhui Provincial Hospital Affiliated to Anhui Medical University, 17 Lujiang Road, Hefei, Anhui 230001, P.R. China

E-mail: ysd196406@163.com

Key words: metformin, oxidative stress, p38 mitogen-activated protein kinase, mesangial cells
These results were similar to those obtained when SB203580 or $\mathrm{N}$-acetylcysteine was added to the high glucose medium $(\mathrm{P}<0.05)$. In conclusion, metformin was suggested to alleviate high glucose-induced oxidative stress and p-p38MAPK protein expression in rat glomerular MCs, which may contribute to its reno-protective abilities in diabetes.

\section{Introduction}

Diabetes is the primary cause of end-stage renal disease(ESRD), which accounts for almost half of all new patients diagnosed with ESRD (1). The pathogenesis of diabetic nephropathy (DN) is complex and indefinite, involving metabolic disorder, activation of the renin-angiotensin-aldosterone system, alteration in glomerular hemodynamics, genetic susceptibility, oxidative stress, an inflammatory reaction and cytokine overexpression (2-8). Hyperglycemia has been reported to promote oxidative stress and the generation of ROS in vivo and in vitro $(9,10)$. Increased levels of ROS result in direct oxidation and damage to DNA, protein, lipid and carbohydrate, and are hypothesized to have a key role in the pathogenesis of chronic diabetic complications $(11,12)$, particularly DN (2). In addition, ROS have been reported to function as signaling molecules, mediating high glucose-induced activation of signal transduction cascades and transcription factors, which in turns leads to transcriptional activation of profibrotic genes in the kidney that are essential for the development and progression of DN (13). A key protective mechanism against oxidative stress-induced $\mathrm{DN}$ is mediated via antioxidant gene induction and/or oxidative gene inhibition (14). Previous studies have indicated that p38MAPK is involved in multiple signal transduction channels in the pathogenesis of DN, activation of which may promote cell proliferation, growth and differentiation $(15,16)$. p38MAPK has been reported to be an essential downstream effector of NADPH oxidase 4 (Nox4) in the signaling pathway that is involved in high glucose and tubular cell injury (17). Metformin is an aminoguanidine derived hypoglycemic agent, which is commonly used in the management of diabetes (18). Multiple clinical trials have confirmed that metformin is able to reduce levels of protein oxidative end-products, advanced glycation end products and ROS, in addition to its hypoglycemic activity (19-21). However, it has not been previously 
reported whether metformin is able to reduce oxidative stress by inhibiting the activity of p38MAPK. The aim of the present study was to investigate the inhibitory effects of metformin on high glucose-induced oxidative stress and p38MAPK expression in rat glomerular mesangial cells (MCs), in order to elucidate its underlying reno-protective mechanisms in vitro.

\section{Materials and methods}

Materials. Rat glomerular mesangial cells (HBZY-1) were obtained from China Center for Type Culture Collection (Wuhan, China). The following material, reagents and kits were used in the present study: Dulbecco's modified Eagle's medium (DMEM; HyClone Laboratories, Inc., Logan, UT, USA), fetal calf serum (HyClone Laboratories, Inc.), trypsin (HyClone Laboratories, Inc.), polyvinylidene fluoride (PVDF) membranes (EMD Millipore, Billerica, MA, USA), metformin (Sigma-Aldrich, St. Louis, MO, USA), 4-(4-fluorop henyl)-2-(4-methylsulfinylphenyl)-5-(4-pyridyl)-1H-imidazole (SB203580; Sigma-Aldrich), N-acetylcysteine (NAC; Sigma-Aldrich), 2',7'-dichloro-fluoresceindiacetate (DCFH-DA; Sigma-Aldrich), phenylmethanesulfonyl fluoride (Sigma-Aldrich), RevertAid First Strand cDNA Synthesis kit and PCR Master Mix (Thermo Fisher Scientific, Waltham, MA, USA), total superoxide dismutase (SOD) assay kits (Nanjing Jiancheng Bioengineering Institute, Nanjing, China), ELISA kit for malondialdehyde (MDA) kits (USCN Life Science Inc., Wuhan, China), p22phox and GAPDH primers (Sangon Biotech Co., Ltd., Shanghai, China), MTT [(3-4,5-dimethylthiazol-2-yl)-2,5-diphenyltetrazolium

bromide; Invitrogen Life Technologies, Carlsbad, CA, USA], TRIzol reagent (Invitrogen Life Technologies) and electrochemiluminescence (ECL) color developing reagent (Pierce Biotechnology, Inc., Rockford, IL, USA). In addition the following primary antibodies were used in the present study: Rabbit monoclonal primary anti-p38MAPK $(1: 1,000$; cat. no. 8690S; Cell Signaling Technology, Inc., Danvers, MA, USA), rabbit monoclonal anti-phosphorylated p38MAPK (p-p38MAPK; 1:1,000; cat. no. 4631S; Cell Signaling Technology, Inc.), rabbit polyclonal anti-p22phox (1:500; cat. no. sc-20781; Santa Cruz Biotechnology, Inc. (Dallas, TX, USA), and monoclonal rabbit GAPDH (1:1,000; cat. no. 2118S; Cell Signaling Technology, Inc.). Goat anti-rabbit horseradish peroxidase (HRP)-conjugated secondary antibodies $(1: 1,000$; cat. no. 7074) were purchased from Cell Signaling Technology, Inc.

Cell viability MTT assay. Rat MCs in the exponential growth phase were cultured in complete medium (DMEM supplemented with $10 \%$ fetal calf serum, $100 \mathrm{U} / \mathrm{ml}$ penicillin and $100 \mu \mathrm{g} / \mathrm{ml}$ streptomycin; North China Pharmaceutical Group Corporation, Shijiazhuang, China) and then seeded into 96-well plates at a density of $5 \times 10^{3}$ cells/well. Different concentrations of metformin $(2.5,5.0,10.0$ and $20.0 \mathrm{mmol} / \mathrm{l})$ were then added. The viability of cells was assessed using the MTT assay, as previously described (22) and the half maximal inhibitory concentration $\left(\mathrm{IC}_{50}\right)$ of metformin was determined.

Cell culture and specimen collection. Rat MCs were cultured in complete medium (as above) in a humidified incubator at $37^{\circ} \mathrm{C}$ and $5 \% \mathrm{CO}_{2}$ and were subcultured every two days. The cells were seeded into 6 -well plates at a density of $1 \times 10^{6}$ cells/well and were divided into the following five groups: Normal control (NC; glucose concentration $5.6 \mathrm{mmol} / \mathrm{l}$ ), high glucose (HG; glucose concentration $30 \mathrm{mmol} / \mathrm{l}$ ), metformin-treated (MET; glucose concentration $30 \mathrm{mmol} / 1$ + metformin final concentration $6.8 \mathrm{mmol} / \mathrm{l}$ ), SB203580-treated (SB; glucose concentration $30 \mathrm{mmol} / 1+\mathrm{SB} 203580$ final concentration $10 \mu \mathrm{mol} / \mathrm{l}$ ) and NAC-treated (NAC; glucose concentration $30 \mathrm{mmol} / \mathrm{l}+\mathrm{NAC}$ final concentration $100 \mu \mathrm{mol} / \mathrm{l})$. Rat MCs and the supernatant were collected after centrifugation at $1,500 \mathrm{x} \mathrm{g}$ for $5 \mathrm{~min}$ at $20^{\circ} \mathrm{C}$, following cell culture for $48 \mathrm{~h}$ at $37^{\circ} \mathrm{C}$ and $5 \% \mathrm{CO}_{2}$.

Detection of intracellular ROS production in rat MCs by flow cytometry. Intracellular ROS production in rat MCs was analyzed fluorometrically by detecting the oxidation of the non-fluorescent probes 2',7' -dichloro-fluoresceindiacetate (DCFH) to the fluorescent metabolites dichlorofluorescein (DCF). Briefly, $10 \mu \mathrm{M}$ DCFH-DA was added to each well of MCs and the wells were incubated for $30 \mathrm{~min}$ at $37^{\circ} \mathrm{C}$. The oxidation of DCFH by ROS was determined by measuring the percentage of cells marked by DCF in a minimum of 10,000 cells using a flow cytometer (Cytomics FC 500 MPL; Beckman Coulter, Brea, CA, USA) at excitation and emission wave lengths of 488 and $525 \mathrm{~nm}$, respectively.

Colorimetric analysis of SOD activity in supernatant fluid. SOD activity in the supernatant fluid was determined by the xanthine oxidase method using SOD kits according to the manufacturer's instructions. Absorbance values of samples were determined at $550 \mathrm{~nm}$ using an ultraviolet spectrophotometer (UVmini-1240; Shimadzu Corporation, Kyoto, Japan). According to enzymatic definition, when the inhibitory ratio of SOD in $1 \mathrm{ml}$ supernatant reached 50\%, the corresponding dose of SOD was considered a vitality unit, which represents the quantity of enzyme that can transform $1 \mu \mathrm{mol}$ substrate in a minute under certain conditions.

Detection of MDA content in the supernatant fluid by ELISA. MDA content in the supernatant fluid was determined using ELISA kits for MDA according to the manufacturer's instructions. Absorbance values of samples were measured at $450 \mathrm{~nm}$ using an ultraviolet spectrophotometer (UVmini-1240) and the MDA content (ng/ml) was determined.

Quantification of p22phox mRNA expression in rat MCs by reverse transcription-quantitative polymerase chain reaction $(R T-q P C R)$. Total RNA was extracted using the TRIzol reagent kit according to the manufacturer's instructions and quantified by measuring the absorbance at $260 \mathrm{~nm}$. RNA quality was then determined by measuring the $260 / 280 \mathrm{~nm}$ ratio. Subsequently, first-strand cDNA was synthesized from total RNA using a RevertAid First Strand cDNA Synthesis kit according to the manufacturer's instructions. The sequences of PCR primers used in the assays are as follows: p22phox forward, 5'-TCCACTTACTGCTGTCCGT-3' and reverse, 5'-TGG TAGGTGGCTGCTTGAT-3' (NM_024160; 185 bp); and GAPDH forward, 5'-ACAGCAACTCCCATTCTTC-3' and reverse, 5'-TGGTCCAGGGTTTCTTAC-3' (163 bp). RT-qPCR 
was subsequently performed using SsoFast EvaGreen Supermix (Bio-Rad Laboratories, Inc., Hercules, USA) and a CFX96 ${ }^{\mathrm{TM}}$ Real-Time PCR system (Bio-Rad Laboratories, Inc.) according to the manufacturer's instructions. Reaction conditions for the PCR were as follows: Enzyme activation at $95^{\circ} \mathrm{C}$ for $30 \mathrm{sec}$ followed by 35 cycles at $95^{\circ} \mathrm{C}$ for $5 \mathrm{sec}, 56^{\circ} \mathrm{C}$ for $5 \mathrm{sec}$ and $72^{\circ} \mathrm{C}$ for $5 \mathrm{sec}$. The threshold cycle $(\mathrm{Ct})$ value for each gene was normalized to the $\mathrm{Ct}$ value of GAPDH. The relative mRNA expression was calculated using the comparative $\mathrm{Ct}\left(2^{-\Delta \Delta \mathrm{Ct}}\right)$ method as previously described $(23,24)$.

Detection of p22phox and p-p38MAPK protein expression in rat MCs by western blot analysis. Rat MCs were rinsed twice with ice-cold phosphate-buffered saline (Bailunsi Biotechnology Co., Ltd., Tianjin, China) and lysed on ice with Cellytic M lysis buffer (Sigma-Aldrich, St. Louis, MO, USA) supplemented with protease inhibitors (Sigma-Aldrich) and phosphorylase inhibitors (Phosphatase Inhibitor Cocktail 2; Sigma-Aldrich) for $30 \mathrm{~min}$. Following centrifugation at $12,000 \mathrm{x} \mathrm{g}$ for $5 \mathrm{~min}$ at $4^{\circ} \mathrm{C}$, total cell lysate extracts were collected and the protein content was determined using the protein assay (Beyotime Institute of Biotechnology, Shanghai, China). A total of $50 \mu \mathrm{g}$ total proteins were separated using SDS-PAGE and transferred onto PVDF membranes. The membranes were blocked with 5\% non-fat milk in Tris-buffered saline containing $0.05 \%$ Tween 20 (Bailunsi Biotechnology Co., Ltd.) for $1 \mathrm{~h}$ and were then incubated with p22phox, GAPDH, p38MAPK or p-p38MAPK monoclonal antibodies at $4^{\circ} \mathrm{C}$ overnight, followed by incubation with a HRP-conjugated secondary antibody for $1 \mathrm{~h}$. Immunoblots were developed using ECL color developing reagent and the chemiluminescence image analysis system (Tanon $5500 \mathrm{Gel}$ Imaging System; Tanon Science and Technology Co., Ltd, Shanghai, China) was used to quantitatively analyze the immunoblot results. The band intensity ratio of p22phox to GAPDH and p-p38MAPK to p38MAPK represented the p22phox and $\mathrm{p}$-p38MAPK protein relative content respectively, while GAPDH or p38MAPK served as the internal reference.

Statistical analysis. A minimum of three repeats were conducted for each experiment. All data are expressed as the mean \pm standard deviation and were analyzed with an analysis of variance using SPSS software, version 13.0 (SPSS, Inc., Chicago, IL, USA). For experiments in which only single experimental and control groups were used, the difference between groups was examined using an unpaired Student's t-test. $\mathrm{P}<0.05$ was considered to indicate a statistically significant difference.

\section{Results}

ROS production in rat MCs. Compared with that of the NC group, ROS production in rat MCs was significantly increased in the HG group $(\mathrm{P}<0.05)$. In addition, ROS production was significantly reduced in the MET, SB and NAC groups, compared with that of the $\mathrm{HG}$ group $(\mathrm{P}<0.05)$ (Fig. 1).

SOD activity in supernatant fluid. Compared with that of the NC group, SOD activity in the supernatant was significantly reduced in the HG group $(\mathrm{P}<0.05)$. By contrast, SOD activity was significantly higher in the MET, SB and NAC groups, compared with that of the $\mathrm{HG}$ group $(\mathrm{P}<0.05)$ (Fig. 2).

MDA content in the supernatant fluid. Compared with that of the NC group, MDA content in the supernatant was significantly increased in the HG group $(\mathrm{P}<0.05)$, whereas MDA content was significantly reduced in the supernatant of the MET, SB and NAC groups compared with that of the HG group ( $\mathrm{P}<0.05)$ (Fig. 3).

p22phox mRNA expression in rat MCs. Compared with that of the NC group, p22phox mRNA expression in rat MCs was identified to be significantly increased in the $\mathrm{HG}$ group $(\mathrm{P}<0.05)$; however, $\mathrm{p} 22$ phox mRNA expression was significantly reduced in the MET, SB and NAC groups compared with that of the HG group ( $\mathrm{P}<0.05)$ (Fig. 4).

p22phox protein expression in rat MCs. Compared with that of the NC group, p22phox protein expression in rat MCs was significantly increased in the HG group $(\mathrm{P}<0.05)$. By contrast, p22phox protein expression was significantly reduced in the MET, SB and NAC groups compared with that of the HG group $(\mathrm{P}<0.05)$ (Fig. 5).

p-p38MAPK protein expression in rat MCs. Compared with that of the NC group, p-p38MAPK protein expression in rat MCs was observed to increase in the HG group $(\mathrm{P}<0.05)$; however, p-p38MAPK protein expression was significantly reduced in the MET, SB and NAC groups compared with that of the HG group $(\mathrm{P}<0.05)$ (Fig. 6).

\section{Discussion}

Oxidative stress has been reported to be an important factor involved in the pathogenesis of diabetic complications, such as DN (25-29). Diabetes is associated with an increase in the generation of ROS in the kidney $(25,27-29)$, which is involved in the accumulation of extracellular matrix in the MCs and glomerulosclerosis. Although there are various sources of ROS in cells and tissues, the major sources of ROS in renal cells were found to be the mitochondrial electron transport chain $(30,31)$ and the Nox family $(32,33)$. Nox4 and p22phox have been identified to be involved in high-glucose-dependent oxidative stress and fibronectin or collagen IV accumulation in MCs $(34,35)$. p22phox mRNA and protein expression were observed to be upregulated by high glucose in these cells in addition to glomeruli from diabetic animals $(34,35)$. Xia et al (36) additionally reported that high-glucose-induced oxidative stress involved the ROS production by $\mathrm{p} 22 \mathrm{phox}$-based Nox, which occurs due to the upregulation of $\mathrm{p} 22$ phox protein in MCs. Increased cellular oxidative stress was previously demonstrated to act as a second messenger for cellular signaling pathways, which in turn activates numerous redox-sensitive transcription factors, and results in cell membrane damage and the inactivation of enzymes (37). Human (2) and animal (38) studies have reported a significant reduction in the levels of SOD and catalase were observed in uncontrolled diabetes, whereas serum levels of MDA were found to be increased. In the current study, the activity of SOD in the supernatant of rat MCs was significantly reduced, whereas the level of MDA, 
A
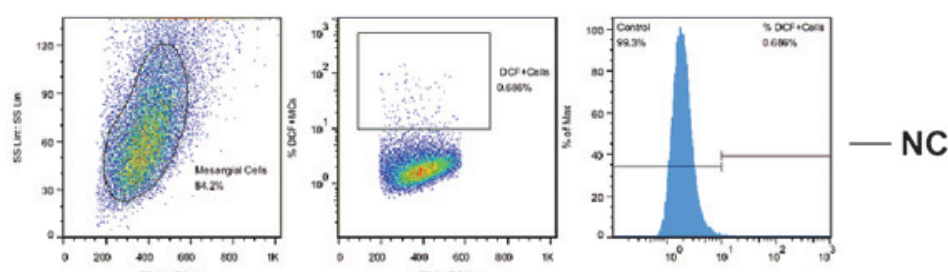

Fsinssis
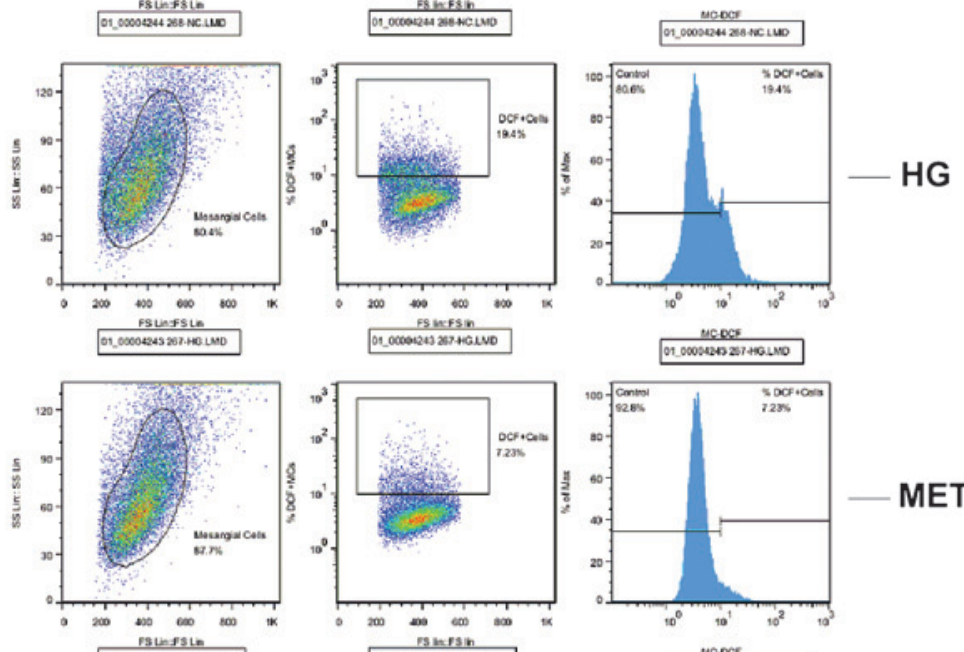

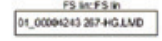
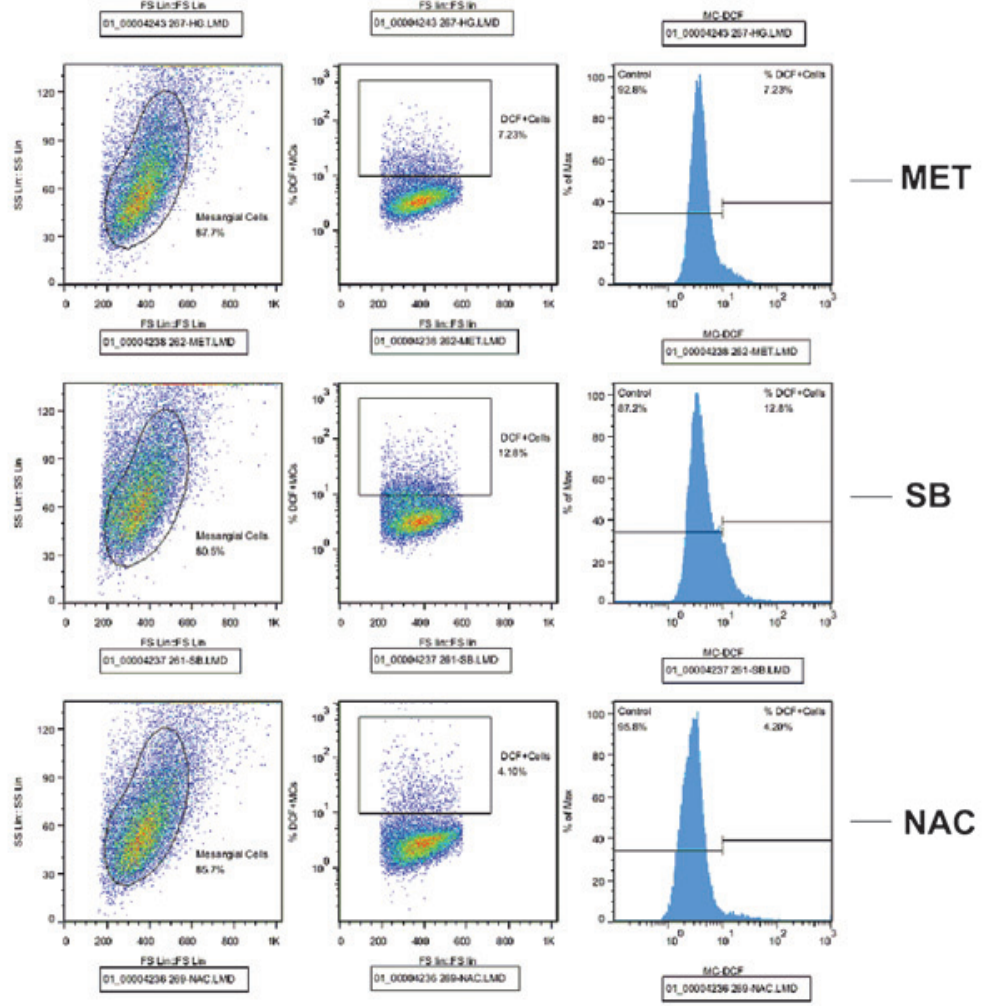

B

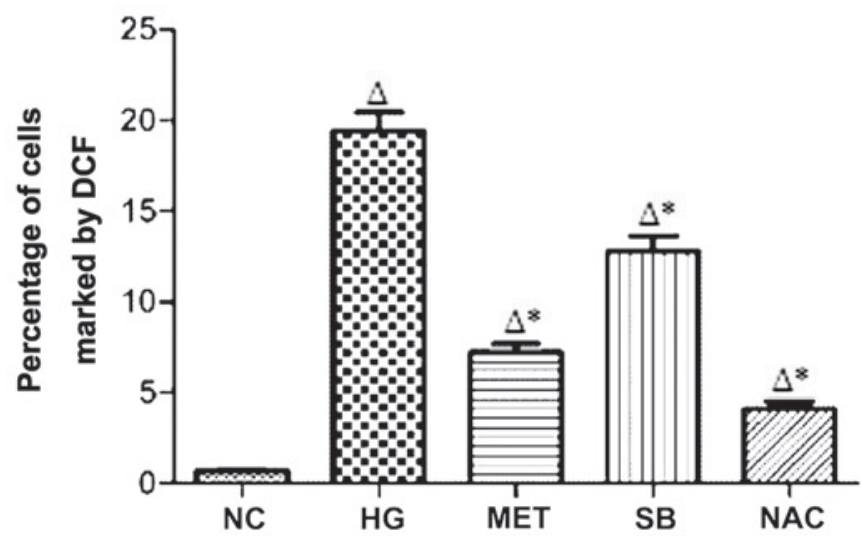

Figure 1. Flow cytometric analysis of rective oxygen species production in different experimental and control groups. (A) The oxidation of the non-fluorescent probes DCFH to the fluorescent metabolites DCF in every group. (B) The percentage of cells marked by DCF in a minimum of 10,000 cells in every group. The values are expressed as the mean \pm standard deviation $\left({ }^{\wedge} \mathrm{P}<0.05\right.$, vs. NC group; ${ }^{*} \mathrm{P}<0.05$, vs. HG group). HG, high glucose; MET, metformintreated; SB, SB203580-treated; NAC, N-acetylcysteine-treated; NC, normal control; DCF, dichlorofuorescein; DCFH, 2',7'-dichloro-fluoresceindiacetate.

intracellular ROS production, p22phox mRNA and protein expression were all identified to increase when rat MCs were cultured in high glucose. This indicated that high glucose induced oxidative stress. 


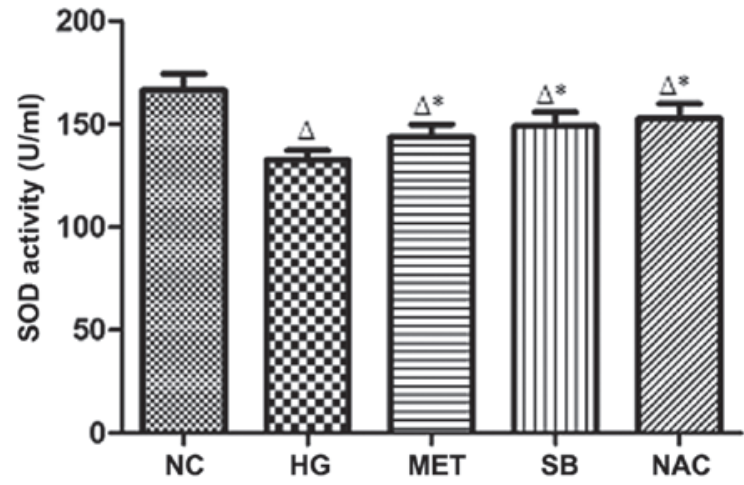

Figure 2. SOD activity in different groups. Values are presented as the mean \pm standard deviation. ${ }^{\triangle} \mathrm{P}<0.05$ vs. the NC group; ${ }^{*} \mathrm{P}<0.05$ vs. the HG group. SOD, superoxide dismutase; HG, high glucose; MET, metformin-treated; SB, SB203580-treated; NAC, N-acetylcysteine-treated; NC, normal control.

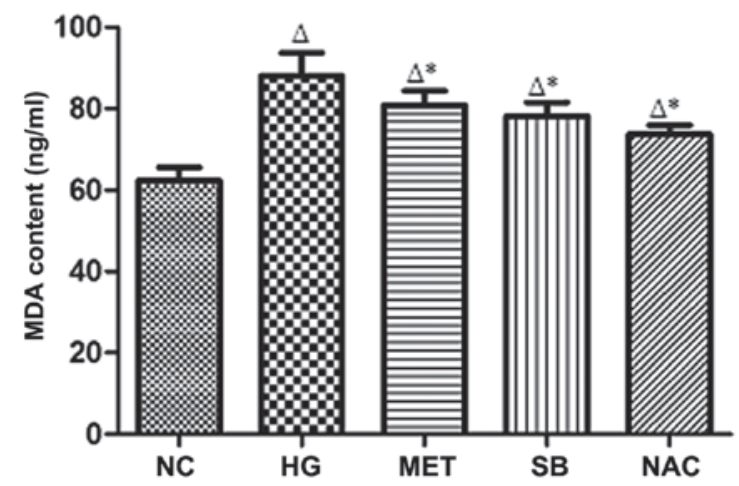

Figure 3. MDA content in different groups. Values are presented as the mean \pm standard deviation. ${ }^{\Delta} \mathrm{P}<0.05$ vs. the $\mathrm{NC}$ group; ${ }^{*} \mathrm{P}<0.05$ vs. the $\mathrm{HG}$ group. MDA, malondialdehyde; $\mathrm{HG}$, high glucose; MET, metformin-treated SB, SB203580-treated; NAC, N-acetylcysteine-treated; NC, normal control.

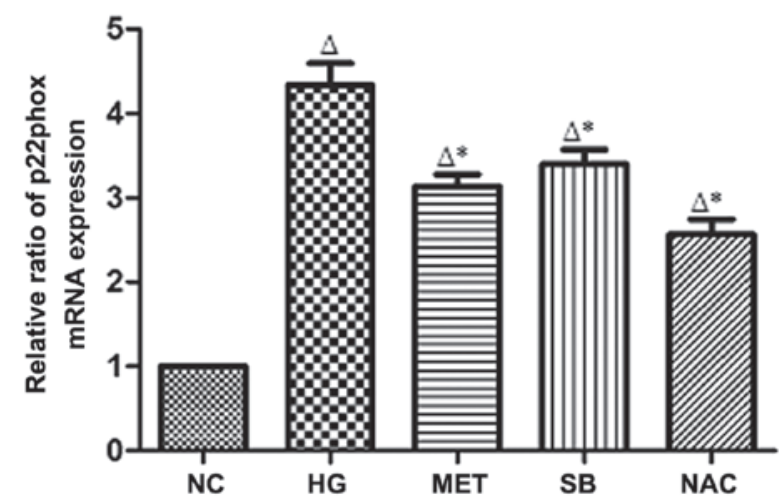

Figure 4. p22phox mRNA expression levels in different groups. Values are presented as the mean \pm standard deviation. ${ }^{\Delta} \mathrm{P}<0.05$ vs. the $\mathrm{NC}$ group; ${ }^{*} \mathrm{P}<0.05$ vs. the HG group. HG, high glucose; MET, metformin-treated; $\mathrm{SB}$, SB203580-treated; NAC, N-acetylcysteine-treated; NC, normal control.

Previous studies have demonstrated that metformin, an oral hypoglycemic drug, exhibits antioxidative effects $(19,39)$. A direct scavenging effect of metformin has also been reported, with studies identifying that metformin acts to remove oxygenated free radicals and ROS generated in aortic endothelial cells, the mechanism of which was found to proceed via the reduction

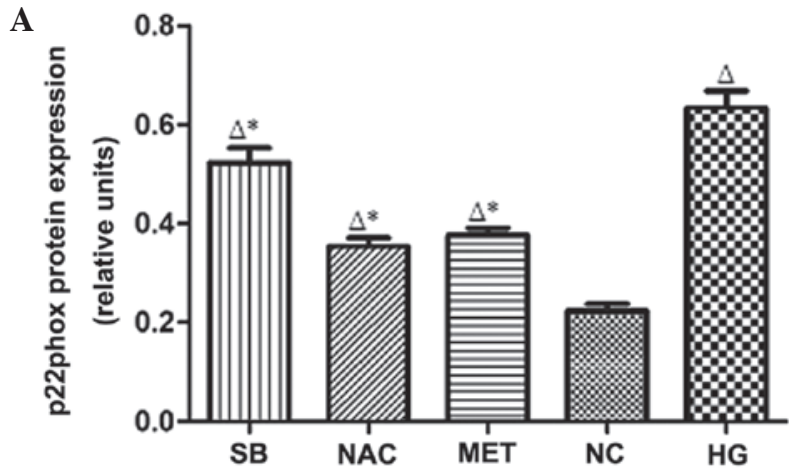

B

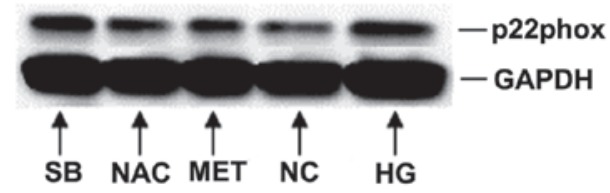

Figure 5. Protein expression levels of p22phox in different groups. (A) The band intensity ratio of the protein expression levels of p22phox to GAPDH in every group. (B) The band intensity of the protein expression levels of p22phox and GAPDH in every group. The values are expressed as the mean \pm standard deviation $\left({ }^{\Delta} \mathrm{P}<0.05\right.$, vs.NC group; ${ }^{*} \mathrm{P}<0.05$, vs. HG group). HG, high glucose; MET, metformin-treated; SB,SB203580-treated; NAC, $\mathrm{N}$-acetylcysteine-treated; NC, normal control.

$\mathbf{A}$

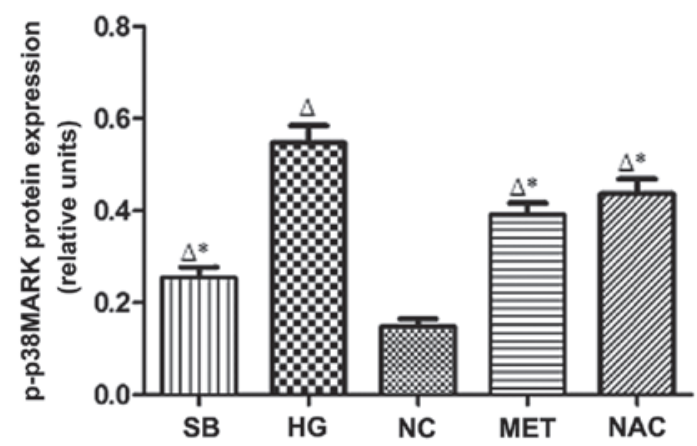

B

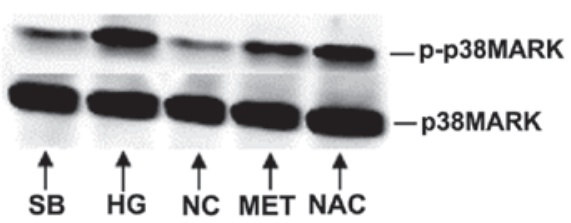

Figure 6. Protein expression of phosphorylated p38MAPK in different groups. (A) The band intensity ratio of p-p38MAPK to $\mathrm{p} 38 \mathrm{MAPK}$ protein expression in every group. (B) The band of p-p38MAPK and p38MAPK protein expression in every group. The values are expressed as the mean \pm standard deviation $\left({ }^{\Delta} \mathrm{P}<0.05\right.$, vs. $\mathrm{NC}$ group; ${ }^{*} \mathrm{P}<0.05$, vs. HG group.p38MAPK, $\mathrm{p} 38$ mitogen-activated protein kinase; p-, phosphorylated; HG, high glucose; MET, metformin-treated; SB, SB203580-treated; NAC, N-acetylcysteinetreated; NC, normal control.

of Nox and/or mitochondrial respiratory chain pathways $(40,41)$. In the current study, in vitro administration of metformin to cultured rat MCs significantly reversed the high glucose-mediated over-production of MDA and intracellular ROS, reversed the overexpression of p22phox mRNA and protein levels as well as improved SOD activity. These results suggested that metformin 
may act to reduce oxidative stress in high glucose-stimulated rat MCs, thus leading to reno-protection, which is in agreement with the results of previous studies $(39,42)$.

Nishida et al (43) reported that ROS are able to induce the activation of p38MAPK in rat neonatal cardiomyocytes, which was in agreement with an additional study using 3T3-L1 adipose cells (44). ROS are also able to promote the activation of p38MAPK in rat MCs cultured in a high glucose medium, which was reversed by antioxidants (45). Song et al (46) identified that SB203580, a p38MAPK inhibitor, reduced MDA content and enhanced SOD activity in rats with spinal cord injury (46). In addition, various previous studies have observed that exposure of cells to $\mathrm{H}_{2} \mathrm{O}_{2}$ results in the activation of p38MAPK, which in turn mediates ROS-induced senescence and oxidative stress-induced autophagy (47-49). The current study observed that oxidative stress marker expression levels and p-p38MAPK protein in rat MCs cultured in a high glucose medium were increased compared with those of the NC group. These effects were reduced by the addition of SB203580 (p38MAPK inhibitor) and NAC (antioxidant), indicating that ROS promotes activation of $\mathrm{p} 38 \mathrm{MAPK}$ in rat MCs, which in turn mediates oxidative stress.

Bae et al (50) reported that metformin resulted in the phosphorylation of p38MAPK in NCI-H292 airway epithelial cells, while an additional study demonstrated that high-dose metformin increased phosphorylation of p38MAPK protein (51). However, metformin has been observed to reduce paclitaxel-elicited p38MAPK phosphorylation in non-small cell lung cancer cells (52). Kappe et al (53) also confirmed that metformin significantly reduces the expression of p38MAPK in glucagon-like peptide-1-secreting cells. The present study demonstrated that metformin alleviated the phosphorylation of p38MAPK protein in rat MCs, which may be partly responsible for its effect in inhibiting oxidative stress in rat MCs stimulated by high glucose.

In conclusion, the current study demonstrated that oxidative stress results in activation of the p38MAPK signaling pathway, which amplifies its cascade reaction to in turn stimulate oxidative stress. Metformin was suggested to be able to alleviate oxidative stress and phosphorylation of p38MAPK protein in MCs cultured with high glucose, which may explain the preventative ability of metformin in DN.

\section{Acknowledgements}

The current study was supported by grants from the Natural Science Foundation of Anhui Province (grant no. 11040606M159) and Anhui Province Natural Science Research Project of China (grant no. KJ2011A157).

\section{References}

1. Collins AJ, Kasiske B, Herzog C, et al: Excerpts from the United States renal data system 2006 annual data report. Am J Kidney Dis 49 (Suppl 1): S1-S296, 2007.

2. Pan HZ, Zhang L, Guo M, et al: The oxidative stress status in diabetes mellitus and diabetic nephropathy. Acta Diabetol 47 (Suppl 1): 71-76, 2010.

3. Kiss E, Kränzlin B, Wagenbla $\beta$ K, et al: Lipid droplet accumulation is associated with an increase in hyperglycemia-induced renal damage: Prevention by liver X receptors. Am J Pathol 182: 727-741, 2013
4. Zain M and Awan FR: Renin Angiotensin Aldosterone System (RAAS): Its biology and drug targets for treating diabetic nephropathy. Pak J Pharm Sci 27: 1379-1391, 2014.

5. Bhaskar LV, Mahin S, Ginila RT and Soundararajan P: Role of the ACE ID and PPARG P12A polymorphisms in genetic susceptibility of diabetic nephropathy in a South Indian population. Nephrourol Mon 5: 813-817, 2013.

6. Duran-Salgado MB and Rubio-Guerra AF: Diabetic nephropathy and inflammation. World J Diabetes 5: 393-398, 2014.

7. Zikou X, Tellis CC, Rousouli K, Dounousi E, Siamopoulos KC and Tselepis AD: Differential membrane expression of toll-like receptors and intracellular cytokine induction in peripheral blood monocytes of patients with chronic kidney disease and diabetic nephropathy. Nephron Clin Pract 128: 399-406, 2014.

8. Ots M, Pechter U and Tamm A: Characteristics of progressive renal disease. Clin Chim Acta 297: 29-41, 2000.

9. Kumar P, Rao GN, Pal BB and Pal A: Hyperglycemia-induced oxidative stress induces apoptosis by inhibiting PI3-kinase/Akt and ERK1/2 MAPK mediated signaling pathway causing downregulation of 8-oxoG-DNA glycosylase levels in glial cells. Int J Biochem Cell Biol 53: 302-319, 2014.

10. Jayakumar P, Pugalendi KV and Sankaran M: Attenuation of hyperglycemia -mediated oxidative stress by indole-3-carbinol and its metabolite 3, 3'- diindolylmethane in C57BL/6 J mice. J Physiol Biochem 70: 525-534, 2014.

11. Swaminathan S and Shah SV: Novel approaches targeted toward oxidative stress for the treatment of chronic kidney disease. Curr Opin Nephrol Hypertens 17:143-148, 2008.

12. Rösen P, Nawroth PP, King G, Möller W, Tritschler HJ and Packer L: The role of oxidative stress in the onset and progression of diabetes and its complications: a summary of a congress series sponsored by UNESCO-MCBN, the American Diabetes Association and the German Diabetes Society. Diabetes Metab Res Rev 17:189-212, 2001

13. Ha H, Hwang IA, Park JH and Lee HB: Role of reactive oxygen species in the pathogenesis of diabetic nephropathy. Diabetes Res Clin Pract 82 (Suppl 1): S42-S45, 2008.

14. Li H, Zhang L, Wang F, et al: Attenuation of glomerular injury in diabetic mice with tert-butylhydroquinone through nuclear factor erythroid 2-related factor 2-dependent antioxidant gene activation. Am J Nephrol 33: 289-297, 2011.

15. Knizhnik AV, Kovaleva OV, Komelkov AV, et al: Arf6 promotes cell proliferation via the PLD-mTORC1 and p38MAPK pathways. J Cell Biochem 113: 360-371, 2012.

16. Lee YL, Chen CW, Liu FH, Huang YW and Huang HM: Aclacinomycin A sensitizes K562 chronic myeloid leukemia cells to imatinib through p38MAPK-mediated erythroid differentiation. PLoS One 8: e61939, 2013.

17. Sedeek M, Callera G, Montezano A, et al: Critical role of Nox4-based NADPH oxidase in glucose-induced oxidative stress in the kidney: implications in type 2 diabetic nephropathy. Am J Physiol Renal Physiol 299: F1348-F1358, 2010.

18. Mediavilla Bravo JJ: Guidelines for the management of diabetes mellitus type 2. Semergen 40: 11-18, 2014 (In Spanish).

19. Chakraborty A, Chowdhury S and Bhattacharyya M: Effect of metformin on oxidative stress, nitrosative stress and inflammatory biomarkers in type 2 diabetes patients. Diabetes Res Clin Pract 93: 56-62, 2011.

20. Esteghamati A, Eskandari D, Mirmiranpour H, Noshad S, Mousavizadeh M, Hedayati M and Nakhjavani M: Effects of metformin on markers of oxidative stress and antioxidant reserve in patients with newly diagnosed type 2 diabetes: A randomized clinical trial. Clin Nutr 32: 179-185, 2013.

21. Abdulkadir AA and Thanoon IA: Comparative effects of glibenclamide and metformin on C-reactive protein and oxidant/antioxidant status in patients with type II diabetes mellitus. Sultan Qaboos Univ Med J 12: 55-61, 2012.

22. Marks DC, Belov L, Davey MW, Davey RA and Kidman AD: The MTT cell viability assay for cytotoxicity testing in multidrug-resistant human leukemic cells. Leuk Res 16: 1165-1173, 1992.

23. Schmittgen TD and Livak KJ: Analyzing real-time PCR data by the comparative C(T) method. Nat Protoc 3: 1101-1108, 2008.

24. Livak KJ and Schmittgen TD: Analysis of relative gene expression data using real-time quantitative PCR and the 2(-Delta Delta C(T)) Method. Methods 25: 402-408, 2001.

25. Forbes JM, Coughlan MT and Cooper ME: Oxidative stress as a major culprit in kidney disease in diabetes. Diabetes 57: 1446-1454, 2008.

26. Giacco F and Brownlee M: Oxidative stress and diabetic complications. Circ Res 107: 1058-1070, 2010. 
27. Kashihara N, Haruna Y, Kondeti VK and Kanwar YS: Oxidative stress in diabetic nephropathy. Curr Med Chem 17: 4256-4269, 2010.

28. Singh DK, Winocour P and Farrington K: Oxidative stress in early diabetic nephropathy: fueling the fire. Nat Rev Endocrinol 7: 176-184, 2011.

29. Stanton RC: Oxidative stress and diabetic kidney disease. Curr Diab Rep 11: 330-336, 2011

30. Kiritoshi S, Nishikawa T, Sonoda K, et al: Reactive oxygen species from mitochondria induce cyclooxygenase-2 gene expression in human mesangial cells: potential role in diabetic nephropathy. Diabetes 52: 2570-2577, 2003.

31. Kitada M, Kume S, Imaizumi N and Koya D: Resveratrol improves oxidative stress and protects against diabetic nephropathy through normalization of Mn-SOD dysfunction in AMPK/SIRT1-independent pathway. Diabetes 60: 634-643, 2011

32. Barnes JL and Gorin Y: Myofibroblast differentiation during fibrosis: role of NAD(P)H oxidases. Kidney Int 79: 944-956, 2011.

33. Bedard K and Krause KH: The NOX family of ROS-generating NADPH oxidases: physiology and pathophysiology. Physiol Rev 87: 245-313, 2007.

34. Xia L, Wang H, Goldberg HJ, Munk S, Fantus IG and Whiteside CI: Mesangial cell NADPH oxidase upregulation in high glucose is protein kinase $\mathrm{C}$ dependent and required for collagen IV expression. Am J Physiol Renal Physiol 290: F345-F356, 2006.

35. Zhang L, Pang S, Deng B, et al: High glucose induces renal mesangial cell proliferation and fibronectin expression through $\mathrm{JNK} / \mathrm{NF}-\kappa \mathrm{B} / \mathrm{NADPH}$ oxidase/ROS pathway, which is inhibited by resveratrol. Int J Biochem Cell Biol 44: 629-638, 2012.

36. Xia L, Wang H, Munk S, Kwan J, Goldberg HJ, Fantus IG and Whiteside CI: High glucose activates PKC-zeta and NADPH oxidase through autocrine TGF-betal signaling in mesangial cells. Am J Physiol Renal Physiol 295: F1705-F1714, 2008.

37. Korashy HM and El-Kadi AO: The role of aryl hydrocarbon receptor and the reactive oxygen species in the modulation of glutathione transferase by heavy metals in murine hepatoma cell lines. Chem Biol Interact 162: 237-248, 2006.

38. Nam SM, Lee MY, Koh JH, et al: Effects of NADPH oxidase inhibitor on diabetic nephropathy in OLETF rats: the role of reducing oxidative stress in its protective property. Diabetes Res Clin Pract 83: 176-182, 2009.

39. Alhaider AA, Korashy HM, Sayed-Ahmed MM, Mobark M, Kfoury $\mathrm{H}$ and Mansour MA: Metformin attenuates streptozotocin-induced diabetic nephropathy in rats through modulation of oxidative stress genes expression. Chem Biol Interact 192: 233-242, 2011

40. Bellin C, de Wiza DH, Wiernsperger NF and Rösen P: Generation of reactive oxygen species by endothelial and smooth muscle cells: influence of hyperglycemia and metformin. Horm Metab Res 38: 732-739, 2006.
41. Mahrouf M, Ouslimani N, Peynet J, et al: Metformin reduces angiotensin-mediated intracellular production of reactive oxygen species in endothelial cells through the inhibition of protein kinase C. Biochem Pharmacol 72: 176-183, 2006.

42. Ouslimani N, Peynet J, Bonnefont-Rousselot D, Thérond P, Legrand A and Beaudeux JL: Metformin decreases intracellular production of reactive oxygen species in aortic endothelial cells. Metabolism 54: 829-834, 2005.

43. Nishida M, Tanabe S, Maruyama Y, et al: G alpha 12/13- and reactive oxygen species-dependent activation of c-Jun $\mathrm{NH} 2$-terminal kinase and p38 mitogen-activated protein kinase by angiotensin receptor stimulation in rat neonatal cardiomyocytes. J Biol Chem 280: 18434-18441, 2005.

44. Zarrouki B, Soares AF, Guichardant M, Lagarde $M$ and Géloën A: The lipid peroxidation end-product 4-HNE induces COX-2 expression through p38MAPK activation in 3T3-L1 adipose cell. FEBS Lett 581: 2394-2400, 2007.

45. Nowak JZ and Wiktorowska-Owczarek A: Neovascularization in ocular tissues: mechanisms and role of proangiogenic and antiangiogenic factors. Klin Oczna 106: 90-97, 2004 (In Polish).

46. Song Y, Liu J, Zhang F, Zhang J, Shi T and Zeng Z: Antioxidant effect of quercetin against acute spinal cord injury in rats and its correlation with the p38MAPK/iNOS signaling pathway. Life Sci 92: 1215-1221, 2013

47. Luo Y, Zou P, Zou J, Wang J, Zhou D and Liu L: Autophagy regulates ROS-induced cellular senescence via p21 in a p38 MAPK $\alpha$ dependent manner. Exp Gerontol 46: 860-867, 2011.

48. Frippiat C, Dewelle J, Remacle J and Toussaint O : Signal transduction in H2O2-induced senescence-like phenotype in human diploid fibroblasts. Free Radic Biol Med 33: 1334-1346, 2002.

49. Tamagno E, Robino G, Obbili A, Bardini P, Aragno M, Parola M and Danni O: H2O2 and 4-hydroxynonenal mediate amyloid-induced neuronal apoptosis by activating JNKs and p38MAPK. Exp Neurol 180: 144-155, 2003.

50. Bae CH, Kim JW, Ye SB, Song SY, Kim YW, Park SY and Kim YD: AMPK induces MUC5B expression via p38 MAPK in NCI-H292 airway epithelial cells. Biochem Biophys Res Commun 409: 669-674, 2011.

51. Hauton D: Does long-term metformin treatment increase cardiac lipoprotein lipase? Metabolism 60: 32-42, 2011.

52. Tseng SC, Huang YC, Chen HJ, et al: Metformin-mediated downregulation of p38 mitogen-activated protein kinase-dependent excision repair cross-complementing 1 decreases DNA repair capacity and sensitizes human lung cancer cells to paclitaxel. Biochem Pharmacol 85: 583-594, 2013.

53. Kappe C, Holst JJ, Zhang Q and Sjöholm A: Molecular mechanisms of lipoapoptosis and metformin protection in GLP-1 secreting cells. Biochem Biophys Res Commun 427: 91-95, 2012. 